\title{
A TEORIA GEOMORFOLÓGICA E SUA EDIFICAÇÃO: ANÁLISE CRITICA
}

\author{
Adilson Avansi de ABREU *
}

\begin{abstract}
RESUMO
O presente trabalho refere-se a uma exposição sucinta da interpretação sobre o desenvolvimento global de ciência geomorfológica. A intenção é definir um sistema referencial em função do qual possa-se obter parâmetros para a interpretação crítica das diferentes posturas assumidas pelos geomorfólogos no correr do tempo.

Fornece ainda, uma sinopse interpretativa que identifica linhas mestras da evolução da geomorfologia, através da filogênese da teoria geomorfológica.
\end{abstract}

\section{ABSTRACT}

The present work deals with the interpretation about the development of geomorphology as a science.

The aim is to give a referencial system to get a parameter concerning a critical interpretation about the different purposes assumed by geomorphologists through the years.

The work also presents interpretative synopsis which identify the basic points of the geomorphological evolution through the geomorphology theory phylogenesis.

\section{O PROBLEMA E SEU ENQUADRAMENTO}

Uma análise crítica da bibliografia geomorfológica, tendo por objetivo a busca de um sistema conceitual ou um paradigma (aqui utilizado na acepção de KUHN, 1970), coerente, que nos permita manter um eixo referencial em função do qual a análise geomorfológica possa ser executada, revela um panorama à primeira vista confuso e pessimista.

Há uma grande variedade de conceitos emitidos, oriundos de posturas frequentemente ao sabor do momento. Poucos autores revelam claramente sua posição face às diversas propostas teóricas e metodológicas, sendo que via de regra, aliás, teoria e método se confundem. A existência de uma referência voltada para a epistemologia da geomorfologia (REYNAUD, 1971) não invalida as observações que faremos, dada as limitações de seu conteúdo (ABREU, 1978), embora tenha ela o mérito de alcançar uma outra dimensão, quando a tomamos como representativa da geomorfologia francesa, que, até a II Guerra Mundial, esteve estreitamente associada ao paradigma davisiano.

Devemos destacar, tratando desta temática, uma obra de fôlego abrangendo o estudo da evolução das idéias relativas ao relevo terrestre. Corresponde ao trabaho de CHORLEY et alii (1964), voltado para a geomorfologia anterior a Davis e que, embora valorizando sobremaneira os autores de língua inglesa, não deixa de mencionar fatos significativos relativos ao papel de pesquisadores de outras origens. Todavia o limite temporal da obra impede uma avaliação das fases posteriores, que, a rigor, são as mais expressivas.

É importante ainda registrar, em nosso meio, o excelente trabalho Controvérsias geomorfológicas, de LEUZINGER (1948), que fornece um pano de fundo muito bom para a análise que pretendemos fazer. Todavia ele não a substitui, pois, já apresenta claramente uma limitação temporal, por um lado, e uma forma diferente de encarar a origem e a evolução do que ele denomina de

\footnotetext{
* Instituto de Geografia da USP - C. Postal 20.715 - São Paulo, SP, Brasil.
} 
"escola alemã de geomorfologia" de outro, na medida que julgamos haver uma superestimação da obra de Walther Penck, em detrimento de outros autores. Vale a pena frisar, porém, que o objetivo de Leuzinger era outro, em função do que, a divergência certamente deixaria de existir.

Desta forma pretendemos expor, ainda que de maneira sucinta, nossa interpretação sobre o desenvolvimento global da ciência geomorfológica, mesmo correndo o risco de sermos acusados de simplificação excessiva. É um risco calculado, todavia, pois a intenção aqui é definir um sistema referencial, em função do qual possamos obter um parâmetro para a interpretação crítica das diferentes posturas assumidas pelos geomorfólogos no decorrer do tempo.

Queremos sublinhar que o nosso objetivo é, antes de mais-nada, fornecer uma sinopse interpretativa que identifique linhas mestras de evolução, embora seja talvez mais adequado falar em filogênese das propostas conceituais do que em epistemologia.

Devemos lembrar ainda que, para alguns pelo menos, é pouco seguro falar-se em uma teoria para a geomorfologia como um todo, na medida que só certos segmentos de seu objeto são passíveis de uma conceituação teórica menos problemática. Neste caso encontram-se por exemplo, os enunciados ligados ao perfil de equilíbrio fluvial, que justamente, são uma das pedras de toque para as proposições vinculadas a uma das correntes concentuais aqui mencionadas. Neste caso teríamos enunciados que poderiam se enquadrar realmente no nível de formação da teoria, segundo a aplicação dos critérios de Hempel, como registra KITTS (1970). O grosso das proposições que não interessam especificamente a esta postura acabariam caindo então no nível de generalização empírica, segundo o mesmo autor.

A apreciação do conjunto das obras aqui relacionadas, (que embora longe de representar toda a produção científica voltada de maneira direta ou indireta para a geomorfologia, parece ser pelo menos, uma amostragem significativa do conhecimento neste campo), permite-nos constatar que a nível de literatura ocidental (entendendo-se como tal a produção científica dirigida para a geomorfologia e produzida por europeus, seus descendentes e povos europeizados) a teoria geomorfológica, em um sentido moderno originou-se a partir de duas fontes prin- cipais, que embora apresentando interferências uma sobre a outra, evoluem frequientemente demaneira paralela, convergindo apenas nos últimos trinta anos para a busca de um quadro de referências mais global. O não reconhecimento deste fato cria sérias dificuldades ao estabelecimento de uma epistemologia da geormofologia atual.

Reconhecemos, inclusive, que poderíamos fazer uma análise considerando uma só seqüência, que se iniciasse com a sistematização dos conhecimentos nos séculos XVIII e XIX, a partir do trabalho de geólogos e engenheiros europeus e norte americanos e se projetasse, de maneira subseqüente, em conceitos emitidos a partir da publicação do "The geographical cycle" (DAVIS, 1899) ou mesmo de outras obras do mesmo autor, anteriores a esta data. De maneira sumária já acenamos para a existência desta linhagem epistemológica a partir do trabalho publicado por Surell em 1841, apud ABREU (1980).

Todavia parece-nos mais legítimo e frutífero reconhecer a presença de certos característicos diferenciando, desde sua gênese, os dois principais centros de origem dos sistemas conceituais que caracterizaram a geomorfologia na primeira metade do século $\mathrm{XX}$. É bem verdade que nos últimos trinta anos há uma tendência a se apagar os contrastes e diminuir as arestas destas duas linhagens de posturas, fruto inclusive da internacionalização do conhecimento, resultante, em boa parte, da expansão do inglês que se firma nesta fase como principal língua de uso internacional. As diferenças, contudo, são ainda vivas e significativas, (HAGEDORN \& THOMAS, 1980).

Parece-nos, inclusive, que especialmente nos primeiros anos do segundo pós-guerra o avanço se fez, de um lado pela insatisfação interna dentro de um desses sistemas conceituais, conduzindo à proposição de paradigmas substitutivos e de outro, por uma crítica mútua mais sistemática entre essas duas linhas de evolução epistemológica, que parece conduzir, nos últimos anos, à uma reformulação mais geral, a qual tende a valorizar cada vez mais o aspecto de geociências, voltada para uma interface complexa e que em termos de aplicação tende a ampliar seus fundamentos ecológicos. Neste sentido, aliás, o sistema teórico referencial deslocase para uma das fontes de origem da teoria geomorfológica. 
Mesmo correndo o risco da simplificação excessiva, parece-nos legítimo, entretanto, sistematizar a evolução do conhecimento geomorfológico da forma que se segue, no concernente aos conceitos básicos de explanação, no que de resto é, até certo ponto concorde, com as observações já registradas por MIKESELL (1969), que vê a própria geografia nascendo nos USA a partir da geologia, via fisiografia, ao passo que na Alemanha ela nasce no bojo de uma concepção abrangente de ciências da terra, emergindo de uma perspectiva naturalista mais globalizante.

Seguimos aliás uma tradição de contrapor uma escola de geomorfologia à outra, como inúmeros autores já o fizeram. Todavia nossa intenção, se por um lado é deslocar a interpretação em relação a importância relativa de alguns autores, por outro é insistir na necessidade de se fazer esta análise subordinada a um quadro de referências que incorpore as relações internacionais e os centros de poder interferindo de diversas formas na evolução da postura geomorfológica.

Assim sendo ,embora nos pareça desnecessário traçar as linhas mestras da história do Ocidente nos séculos XVIII, XIX e $\mathrm{XX}$, devemos ter em mente a evolução destes acontecimentos para explicar certas características e originalidades de cada face da moeda.

O início do pensamento geomorfológico, como de resto a própria geologia, vai ser profundamente marcado de um lado pela conquista do oeste americano e de outro pelos fatos que vieram no bojo da Revolução Industrial, entre os quais, além daqueles vinculados à definição dos impérios coloniais, emerge uma profunda mudança no pensamento científico europeu, decorrentes das pesquisas vinculadas à prospecção mineral.

Desta forma se na América do Norte desde cedo valorizaram-se as observações que vinculam o trabalho dos rios ao modelado do relevo, o que é muito destacado nas pesquisas dos geólogos do século XIX que percorrem as áreas além-Apalaches, na Europa a evolução tem como ponto de partida outro sistema de referências, embora nem por isso se deve negar a participação de engenheiros que também se dedicaram ao estudo dos rios e seu comportamento. Todavia aí preponderou, particularmente na Alema- nha, de um lado, a postura que grandes naturalistas já haviam esboçado desde os fins do século XVIII e de outro, as observações oriundas de uma análise sistemática da crosta, a partir da engenharia de minas. A busca dos combustíveis fósseis para alimentar em fontes de energia a industrialização do Império Alemão, que rapidamente suplanta a Inglaterra, acaba dando o acento em uma postura que encara a tectônica de outra forma. Neste sentido achamos que não é apenas o contexto fisiográfico diferenciado da América do Norte e da Europa que justifica as óticas divergentes que presidem o início da geomorfologia e dá um acento nos processos climáticos ou na dinâmica interna, segundo o autor considerado, no segundo caso ou nos processos fluviais, no primeiro caso.

A diferenciação das posturas é fruto de um caldo de cultura que se desenvolve em um contexto político de definição de quadros nacionais contrastantes e que presidem uma orientação diferente em cada caso. Basta lembrar que se Humboldt e Goethe são universais, a solidez da presença desses nomes é muito maior em um caso do que em outro.

Não parece necessário insistir, por outro lado, que a Inglaterra e a França aproximam-se, desde os alvores do século, em relação aos Estados Unidos e logo emerge em sistema de confrontação que coloca freqüentemente Berlim em oposição às 3 capitais ocidentais. Porém é importante frisar que isto se reflete também na produção científica e a Segunda Guerra não apaga esta tendência, na medida que a confrontação continua em outro contexto: o poder desloca-se mais para leste, porém Berlim ainda se faz presente.

De maneira esquemática temos, como já frisamos, duas linhagens epistemológicas balizando a definição do campo de interesse da teoria e do método de investigação em geomorfologia: uma de raízes norte-americanas e incorporando o grosso da produção em língua inglesa e francesa até a II Guerra Mundial e outra de raízes germânicas, exprimindo-se basicamente de início em alemão (espécie de língua franca da Europa Centro-Oriental), mas que incorpora também, posteriormente, grande parte da produção publicada em russo e polonês. TRICART (1965) p.56 a 75 identifica essas duas tendências, porém articula estes fatos 
em outro contexto de análise, o que resulta em um empobrecimento da interpretação.

A evolução dessas duas linhas conceituais é bastante diferenciada e apresenta inclusive interferência mútuas: enquanto a primeira, de raízes norte-americanas, sofreu muito claramente nos últimos anos os impáctos das "revoluções científicas", com tentativas de ruptura e definição de novos pararadigmas, a segunda, de raízes germânicas, parece evoluir de maneira mais contínua, o que se reflete em um enriquecimento progressivo do paradigma, que ganha complexidade metodológica e operacional, conservando sempre um núcleo comum desde sua origem.

Quando se considera, como o faz TRICART (1965) p. 62 "Davis doit être consideré comme le fondeteur de la géomorphologie en tant que discipline spécialisée. Il lui donna, en effet un corps de doctrine coherent et affirma son originalité", que Davis é o fundador da geomorfologia, o mínimo a se constatar é que há pelo menos um desvio de ótica, o qual faz com que se atribua ao primeiro paradígma de uma linha de evolução epistemológica o papel de certidão de nascimento da geomorfologia. Em sua grande maioria esses autores pertencem ao quadro daqueles que por uma ou outra forma integram esta corrente de conceitos, aceitando-a ou contestando-a e buscando novos paradigmas. Por comodidade chamemos esta corrente de anglo-americana, embora seja injusto não chamar a atenção para o fato de interessar também a autores de expressão francesa, que do ponto de vista epistemológico vão claramente à reboque da língua inglesa. Pelo mesmo motivo chamaremos a outra corrente de alemã, embora incorpore também autores de línguas eslavas e escandinavas, interessando ainda, embora de forma menos expressiva a autores de outras línguas.

Antes de nos determos em cada um destes "troncos" de evolução conceitual da geomorfologia, queremos ainda chamar a atenção para o fato de que a compreensão da dinâmica temporal das posturas sucessivas, deve incorporar as interferências permanentes que elas exerceram concomitantemente entre sí. Quase que se pode parafrasear PASSARGE (1931) p. 178, dizendo que cada conceito emitido traz consigo mesmo as resistências para sua aceitação pelo outro inter-locutor.

\section{A LINHAGEM EPISTEMOLÓGICA ANGLO-AMERICANA}

Caracteriza-se esta corrente por ter-se apoiado até praticamente a II Guerra Mundial, principalmente no paradígma proposto por Davis, em trabalhos publicados nas últimas duas décadas do século XIX e sistematizado de maneira magistral em 1899 no Geographycal Cycle, no qual o relevo surgia como função da estrutura geológica, dos processos operantes e do tempo, dando este último a tônica em um modêlo que valorizava particularmente o aspecto histórico.

O sucesso da postura davisiana foi grande e rápido no mundo de língua inglesa e francesa. Sua permanência no tempo pode inclusive ser avaliada através do significicado que ele ainda tem na nona edição da obra monumental de MARTONNE (1950), que tanto influenciou nosso meio científico.

Todavia desde a divulgação de suas idéias encontrou Davis seus críticos, particularmente no meio intelectual germânico contemporâneo, que com ele conviveu durante sua permanência em território alemão, em época de grande brilho da Gesellschaft fuer Erdkunde zu Berlin. Para um maior detalhamento das controvérsias que emergiram nesta fase entre Davis e seus opositores e que posteriormente se acirraram, remetemos diretamente para LEUZINGER (1948), que faz um bom apanhado do problema.

Essas controvérsias, aliás, já tinham chegado até nós, mesmo a nível dos manuais de geografia física - que normalmente estão em grande descompasso com a aquisição dos conhecimentos mais recentes da ciência através da tradução que Lyon Davidovich publicou em 1934 da obra de S. Günther, à qual voltaremos a nos referir oportunamente.

As críticas feitas à esse paradígma foram incorporadas de maneira parcial e discutível pelo próprio Davis, mas muito mais, provavelmente, pelos seus seguidores e não se refletiram na reformulação de suas premissas, mas sim na variação dos processos intervenientes, desenvolvendo-se então os trabalhos que desembocaram em dois clás sicos: um da lavra de COTTON (1942) e outro de BIROT (1960). Este último, aliás, registra nesta data e em nosso meio o descompasso francês em relação à geomorfologia, embora colocando o problema em um contexto indiscutivelmente mais atual, evi- 
denciando a dificuldade e a problemática da periodização, que é muito mais válida para as "áreas centrais" do que para as "áreas periféricas" à origem e evolução dos conceitos.

Evidentemente poderíamos lembrar aqui uma lista enorme de trabalhos feitos por geomorfólogos de grande gabarito, especialmente ingleses e franceses, apoiados neste paradigma. Todavia preferimos omití-los, na medida que em pouco alteram o dado central da proposta davisiana. Neste sentido, os dois nomes lembrados são, antes de mais nada, exemplos em uma lista de clássicos.

Sem entrar no mérito deste paradigma, por o julgarmos por demais conhecido, seu aspecto finalista e a pouca atenção que dedicou aos processos em operação, iriam conduzir a geomorfologia norte americana a um isolamento crescente nos próximos anos em relação às ciências da natureza em geral e da geologia em particular. Dentro da própria geografia física a geomorfologia pouco ou nada iria se articular com a climatologia e a biogeografia.

À medida porém que novos esforços para se assimilar as críticas eram desenvolvidos, passava-se também a uma posição de revisão progressiva das premissas davisianas e emergia aos poucos uma atitude de interesse, pelo menos, em relação as alternativas sugeridas pelos críticos.

Nesse sentido, um evento do fim da década de 30 confirma o interesse nortë-americano pela crítica à sua postura, que face às características da proposta davisiana, aparecem mais claramente na obra de Walther Penk. Em 1939 realiza-se em Chicago um simpósio sobre a contribuição deste autor à geomorfologia. As teses e discussões que marcaram esse evento foram publicadas em um número especial dos Anais da Associação dos Geógrafos Americanos, tendo ENGELN (1940) como seu coordenador.

A análise dos resultados posteriores a esta reunião, não tanto dos contidos nos Anais do Simpósio, mas expressos na produção científica, parece demonstrar que as seguintes considerações feitas por PENCK, (1953) p. 9 no início da década de 20 tiveram seus frutos: "To begin with, it is obvious that the ideal forms, which are supposed to develop on a stationary block, can be deduced successfully only if there are no gaps in our knowledge of the essential characteristics of the denudational processes.
Should this pre-requisite not be fullfilled, the deduction is nothing but an attempt to find out from the land forms alone both the endogenetic and the exogenetic condition to which their owe their origin. It is like trying to solve an equation having three quantities, two of which are unknown; we can expect only doubtfull results. The American school may be justifiably reproached with no considering it their next task to eliminate one of the unknown quantities by systematically investigating the processes of denudation all over the world. Un the whole, their part in throwing light upon the exogenetic processes has been a very modest one".

Já nos anais do referido simpósio merece destaque o registro de LEIGHLY (1940), p. 225 sobre o erro de Davis ao assumir que os processos envolvidos na evolução do relevo seriam conhecidos. Este evento acaba também sendo claramente incorporado por ENGELN (1942), que dedica um capítulo especial de sua obra ao que ele denomina "sistema geomorfológico de Walther Penck", onde chama a atenção para a tônica que se deveria dar no futuro ao estudo das vertentes e aos processos a elas associados.

Vale a pena portanto registrar a interpretação que PENCK (1924) deu ao ciclo geográfico e a forma como ela foi incorporada pelos seguidores de Davis. É o limiar da contestação do paradigma anterior e a preparação do terreno para o advento de novos paradigmas, dentro de um contexto norteamericano. Não se pode inclusive esquecer o papel que a tradução da "Die Morphologische Analyse" para o inglês, publicada em 1953, desempenhou, na medida que se tornou mais acessível à grande maioria dos geomorfólogos envolvidos nesta linha de evolução epistemológica da geomorfologia.

Todavia não se pode olvidar que neste momento eclode a II Guerra Mundial e, à seguir, uma boa parte do pensamento científico alemão será incorporado pelos norteamericanos; particularmente técnicas serão implementadas com posturas filosóficas bem definidas. Este é provavelmente um impacto e uma interferência maior ainda que o Simpósio de Chicago, dado os desdobramentos que registrará. Neste sentido já podemos adiantar que se Lester King pode ser explicado com o Simpósio de Chicago, os outros devem ser vistos no contexto da cibernética.

Provavelmente o autor e a obra que mais refletem uma tentativa de se incorporar o 
modelo penckiano a essa corrente de pensamento é KING $(1953,1956,1967)$, que já nos anos cincoenta percorre o Brasil, coletando dados para implementar sua teoria da pediplanação, KING (1967), p. 159-169, que posteriormente com modificações tem sido uma das pedras de toque de grande número de pesquisadores na interpretação do relevo do Brasil.

$\mathrm{O}$ advento desta alternativa, porém, não superou a insatisfação que se tornava crescente, particularmente nos USA e alguns autores passam a assumir, progressivamente, uma atitude mais crítica, esforçando-se concomitantemente na elaboração de outros paradigmas em um contexto que pode ser perfeitamente enquadrado em uma fase revolucionária, segundo a concepção de KUHN (1970).

Assim é que se Davis havia valorizado o tempo, a tônica passará a ser dada ao espaço; se Davis era encarado como responsável por uma postura subjetiva e verbalista, fruto de uma concepção bergsoniana dedutivista, passar-se-á a valorizar fatos encarados como objetivos, estudados através da quantificação; se se julgava que Davis havia desconsiderado os processos, valorizarse-ão agora as relações que exprimam esses processos, e assim por diante.

Pode-se, desta forma, de maneira bastante segura identificar-se uma fase de descontentamento, crítica e procura de um novo paradigma que caracterizou a geomorfologia de língua inglesa, de u'a maneira permanente, desde os anos quarenta, tendo be revelado muito mais fértil na década de cincoenta e início dos anos sessenta, coincidindo com a fase de divulgação e aplicação generalizada da teoria das redes; da teoria dos gráficos, da teoria dos conjuntos, da teoria da informação, através da cibernética BERTA LANFFY (1973) e com o uso generalizado de quantificação, através de computadores.

Durante esta época valoriza-se especialmente a análise espacial e o estudo de bacias de drenagem, estando os resultados mais significativos deste período divulgados entre nós através de duas traduções publicadas em meados da década passada: Modelos Integrados em Geografia CHORLEY \& HAGGETT (1974) e Modelos Físicos e de Informação em Geografia CHORLEY \& HAGGETT (1975). Por achar desnecessário maiores detalhes, lembramos apenas tratar-se da fase de maior impácto entre nós da chamada "revolução quantitativa" que aqui chegou, como era de se esperar, com certo grau de retardamento e que já foi bem explorada por outros autores, particularmente MONTEIRO (1980).

Pode-se dizer que as posturas novas começam a emergir principalmente com HORTON (1945), STRAHLER (1950, 1952, 1954), CRICKMAY, (1959), HACK (1960) e CHORLEY (1962). O conhecimento que se desenvolveu a partir de então está, com exceção das postulações de Crickmay, bem representado na obra editada por CHORLEY (1972) e na publicação de GREGORY \& WALLING (1973), sob o título de "Dainage Basin: Form and Processes, a geomorphological approach".

Extremamente interessante é registrar que a teoria do equilíbrio dinâmico revivida por HACK (1960) e muito divulgada em nosso meio, retornou à cena no ano seguinte à publicação do trabalho de CRICKMAY (1959), que desafiou através de outro paradigma, o princípio global de atividade igual sobre o qual ela se apoia, por meio de sua teoria do princípio de atividade desigual. Esta perspectiva foi por ele aplicada em sua pesquisa sobre a atividade lateral do rio Penbina, afluente da margem direita do rio Atabasca, CRICKMAY (1960) e os resultados parecem ter reforçado seu ponto de vista em relação aos mecanismos globais de evolução do relevo, resultantes de processos superficiais de intensidade muito diferenciadas. É a relatividade dessa diferença que o levou a valorizar os termos processos ativos e processos estagnados, aplicando os primeiros para aqueles comandados pela ação dos rios no caso estudado.

Com exceção de SCHEIDEGGER (1961), este paradigma pouca atenção recebeu, mesmo por parte dos geormofólogos norte-americanos, raras vezes sendo lembrado em nosso meio. Parece-nos todavia que ele tem certa coerência com os fatos observados e que seu teste deveria ser tentado com mais freqüência, ainda que, à primeira vista sua postura possa ser tida como discutível.

Depois da efervescência dos anos $40 \mathrm{e}$ 50, a maior parte dos anos 60 e começos da década de 70 registraram, de certa forma, uma atitude de aplicação dos postulados anteriormente obtidos, através de técnicas quantitativas de sofisticação crescente à serviço de uma análise sistemática do relêvo. Aos poucos emerge também uma teoria pro- 
babilística para explicar a gênese global das formas, cuja fundamentação mais recente talvez seja aquela feita por SHEREVE (1975.)

Uma análise crítica da produção geomorfológica dos últimos trinta anos, todavia, não é muito animadora, como já registraram MOSLEY \& ZIMPFER (1976). A rigor ao paradigma de Davis acrescentou-se o de King, que incorpora parcialmente o anterior e a postura penckana (mal compreendida, segundo THORNES \& BRUNSDEN (1977). A teoria do equilíbrio dinâmico e a teoria probabilística parecem ter tido o mérito de tentar, através da quantificação, um rigor maior para a explanação geomorfológica, porém acabaram caindo, em certos casos extremos, em formulações em grande parte estéreis e de aplicação, na melhor das hipóteses, pelo menos duvidosa. À teoria do princípio de atividade desigual pouca atenção foi dada, embora ela talvez contenha idéias extremamente úteis e contestadoras em relação à postura cíclica.

MOSLEY \& ZIMPFER (1976), p. 382, retratam esta situação de maneira bastante clara: ... "the present situation is un comfortably like that during the "Davisian era", methods such as those of statistical analysis are being used without being understood, and ideas have been widely adopted without the exhaustive testing necessary for their validation. There are disturbing signs in the current literature that geomorphology is not making the advances that seemed inevitable in the 1960's."

Segundo os mesmos autores esta situação é reflexo $1 .^{\circ}$ de uma metodologia pouco sofisticada, $2{ }^{\circ}$ da rejeição do paradigma davisiano sem sua substituição por outro universalmente aceito e $3 .^{\circ}$ da tendência em se considerar um método como o melhor, do que decorre uma rejeição dos demais, p. 382-383. Nós insistiríamos no segundo aspecto lembrado, na medida que os métodos freqüentemente emanam ou se ajustam às teorias de suporte. O terceiro aspecto parece ser inerente da condição humana, mas que na ciência deve ser combatido.

Por outro lado é fundamental registrar que esta situação foi atingida pela emergência de posturas que valorizaram excessivamente o espaço e as supostas relações entre os processos em operação no presente, deixando de lado as considerações temporais, na medida em que estas eram julgadas com- prometidas com o paradigma davisiano. $\mathrm{O}$ descabido dessa atitude foi bem demonstrado por SCHUMM \& LIGHTY (1965) e retomado por THORNES \& BRUNSDEN (1977).

As posturas de MOSLEY \& ZIMPFER (1976) e THORNES \& BRUNSDEN (1977), parecem marcar uma forma de rever, na segunda metade da última década, as propostas precedentes. Perseguem o mesmo intento, porém por vias diferentes .Enquanto os primeiros sugerem o conceito de "areal differentiation of landforms" como base para um paradigma geomorfológico que incorpore todas as formas possíveis de explanação, através de uma analogia com a análise de variância, os segundos procuram classificar os tipos de modelos passíveis de uso, a partir de uma estrutura têmporo-espacial disposta em ordens que vão de 0 a 4 .

É, de certa forma, uma atitude de reflexão conciliadora, que à rigor não introduz novos paradigmas, mas que, todavia, procura reinterpretar os anteriores segundo uma posição crítica mais liberta de preconceitos, tendo os problemas de escala como baliza de referência e voltando a revalorizar as observações de campo, em boa parte eclipsadas no bojo das posturas que privilegiavam a quantificação à partir de dados obtidos, geralmente, de cartas topográficas, fotos aéreas e anuários estatísticos.

Os anos oitenta parecem se iniciar com uma visão pluralista da geomorfologia, segundo palavras textuais de GRAF et alii (1980) p. 280, que consideram englobar seu campo agora "not only those with a geological or geographic background, but also benefits from contributions of hydrologists, pedologists, foresters, and enginees - and even some who consider themselves to be primarily cultural geographers. Other developments are an increased dependence on field research (an old tradition revisited) more realistic expectations from search tools, a ressurgence of interest in manland relationships with a concomitant dependence on the historical approach, an expanded appreciation of the hydrologic cycle, a reinvestigation of morphogenetic regions, new interest in planetary surfaces other than earth's, more detailed is vestigations of event magnitude and frequency, and an involvement with applied problems".

Provavelmente estamos também entrando em uma fase de incorporação mais refletida 
de conceitos originados da outra fonte epistemológica aqui considerada e em uma progressiva universalização dos pontos de referências fundamentais para a definição do "construto" geomorfológico, ao mesmo tempo que se faz um esforço sob o patrocínio da NASA, para se ampliar os limites do campo de estudo, com o objetivo de incorporar também a investigação do relevo de outros corpos celestes (ENZMANN, 1968).

\section{A LINHAGEM EPISTEMOLOGICA ALEMÃ}

Deixando de lado as considerações sobre os predecessores, pode-se dizer que a moderna geomorfologia centro-européia de expressão alemã tem em von Richthofen uma baliza que serve de referência inicial. É, aliás, significativo que julgando as classificações das formas de relêvo propostas por Davis e von Richthfen, segundo transcrição de CHORLEY et alii (1964) p. 619, Mcgee tenha julgado em 1888 ambas ... "more acceptable, since they are based in part on conditions of genesis".

Todavia é indispensável lembrar que se Davis tinha em sua retaguarda principalmente grandes nomes que eram antes de tudo geólogos, von Richthofen tinha como predecessores um conjunto de autores que eram antes de mais nada naturalistas e que tinham em Goethe um ponto de referência permanente.

É significativo e merece destaque o fato de até hoje ser utilizado com freqüência a expressão morfologia, introduzida nas ciências naturais por Goethe, como sinônimo de geomorfologia. Neste verbete é que vamos encontrar, por exemplo, no "Kosmos Taschenlexikon" , de VOGT (1971) a conceituação de geomorfologia e embora o "Geologisches Wörterbuch" de MURAWSKI (1977) registre o substantivo geomorfologia, também acena para uma vinculação com a expressão oriunda da obra de Goethe.

Se admitirmos ser von Richthofen o primeiro a formalizar através de seu "Führer für Forschungsreisende" (1886) o advento de uma linha epistemológica para a geomorfologia centro e leste européia, vale a pena acenar para a diferença entre esta obra e o “The geographical cycle” (1899). Enquanto este é uma proposição teorizante, aquele é um guia para observações. Valoriza-se, portanto, desde o início uma perspectiva empí- rico-naturalista, dentro de um sistema conceitual que até recentemente tem insistido muito neste aspecto, no quadro das geociências em língua alemã (BUBNOFF, 1954).

Todavia a geomorfologia de língua alemã tem igualmente uma origem menos marcada por um só nome e antes que se escoasse uma década após a publicação do "Führer für Forschungsreisende" aparece, em dois volumes, o "Morphologie der Erdoberflaeche" (PENCK, 1894). Os autores destes trabalhos são, aliás, freqüentemente citados como os "pais" da geomorfologia de língua alemã.

Um fato importante a destacar é que von Richthofen e A. Penck tiveram um antecessor, O. Peschel, que todavia vincula-se muito mais às posteriores proposições devisianas que à subseqüente geomorfologia da tradição (RICHTHOFEN, 1886; PENCK (1894) fato, aliás, já levantado por TATHAM (1951), merecendo registro também por CHORLEY et alii (1964).

Esta orientação, todavia, não foi a que se impôs no espaço cultural alemão. As posturas naturalistas valorizadas pela herança de Goethe e Humboldt, imprimiram um direcionamento mais para a observação e análise dos fenômenos em um contexto onde a geomorfologia se relacionava de maneira mais intensa principalmente com a petrografia, química do solo, hidrologia e climatologia. Logo no início a cartografia é mobilizada como um dos instrumentos fundamentais para o pesquisador, o qual tem na observação o centro de seu interesse .

O grande papel do "Führer für Forschungsreisende" foi exatamente o de definir um conjunto de informações, oriundas dos trabalhos executados pelo seu autor na América do Norte, Ásia e Europa, de natureza metodológica no referente à observação dos fatos. É considerado, por quase todos, como o primeiro manual de geomorfologia moderna, sendo estranhável que CHORLEY et alii (1964) tenham lhe dispensado tão pouca atenção, preferindo ressaltar a obra sobre a China.

Já o papel do "Morphologie der Erdoberfläche" PENCK (1894) foi mais o de sistematizar teorias e formas de relêvo, tornando-se um clássico da geografia, nas palavras de LEUZINGER (1948). Por outro lado não se pode deixar de mencionar que sua influência foi tão grande ao ponto de levar a uma verdadeira dominância dos estudos geo- 
morfológicos no contexto da geografia alemã nas primeiras décadas do século XX.

É também de se registrar que tanto $\mathrm{F}$. F. von Richthofen como A. Penck tiveram um papel fundamental na orientação da geografia alemã, na medida em que exerceram forte influência durante mais de meio seculo na condução da Gesellschaft fuer Erkunde zu Berlin, fundada em 1828. A. Penck foi, aliás, seu presidente até 1930, tendo porém grande ascendência nesta associação científica até bem próximo de sua morte, que se deu a 7 de março de 1945, aos 87 anos de idade. Este período coincide, praticamente, com o da ascenção prussiana e a afirmação alemã.

Provavelmente a presença destes dois cientistas à frente da Gesellschaft fuer Erkunde zu Berlin, explique, em parte, a pouca influência que a postura davisiana alcançou no espaço cultural-alemão. É possível, inclusive, que para isto tenha contribuído, em parte, uma certa dose de nacionalismo de raízes prussianas, uma vez que a análise das publicações patrocinadas por esta sociedade permite perceber claramente a vinculação com certas temáticas desta natureza (QUELLE, 1953).

Assim embora Davis estivesse presente na Alemanha entre 1908 e 1909 e publicasse em 1924 sua célebre "Die erklaerende Besschreibung der Landformen", suas proposições produziram, quase imediatamente, acerbadas críticas por parte de um conjunto de pesquisadores afeitos à investigação de espaços com natureza climática muito diversificada. O próprio A. Penck, já em 1912, estabelecera relações entre as formas de relêvo e os cinturões climáticos do planeta, no que fora precedido por J. Walther, no mesmo ano e seguido por W. Voltz, em 1913 e K. Sapper e F. Thorbecke, em 1914 (STRATIL-SAUER, 1968).

Fato também muito importante para justificar essa postura predominante na Europa Centro-Oriental, em relação às proposições de Davis é que desde o fim do século passado já se havia traçado um panorama global, que sugeria, com bastante clareza, um zoneamento dos fenômenos da natureza na face da Terra em estreita dependência com os climas. Assim é que V. Dokuchayeu já havia publicado em 1883 sua obra sobre os solos chernozens da Rússia e, em 1900, W. Köppen lançava sua primeira versão dos climas da Terra (CHORLEY et alii, 1964). Nesta atmosfera intelectual o solo era pouco propício à semeadura davisiana.

Dentro desta corrente três autores marcaram sua presença no início do século e merecem, por motivos diferentes, especial destaque: A. Hettner, S. Passarge e S. Günther.

HETTNER $(1921,1927)$ é, sem dúvida alguma, o grande crítico do ponto de vista do método da proposição davisiana. LEUZINGER (1948) e STRATIL-SAUER (1968) resumem suas observações de maneira bastante clara, o que nos dispensa de maiores comentários.

S. Passarge teve porém um papel mais positivo, na medida que se caracterizou nem tanto pela crítica, mas pela proposição de novos conceitos, trabalhando em uma linha de análise mais global das formas de relevo, integrando-as em uma visão geográfica da paisagem e de um novo método de trabalho, baseado na cartografia geomorfológica (KLIMASZEWSKI, 1963). De sua obra destacam-se três fundamentais: em 1912 surge a "Morfologia Fisiológica" ("Physiologische Morphologie"), entre 1919 e 1920 os "Fundamentos da Ciência da Paisagem" ("Die Grundlagen der Landschaftskunde") são publicados em três volumes e, finalmente, em 1922 vem à luz "As Zonas paisagísticas da Terra" ("Die Landschaftsgürtel der Erde"). Só a titulação dos trabalhos já nos acena para a importância dos conceitos enunciados, entre os quais o de fisiologia da paisagem desponta como corolário.

S. Günther não tem a envergadura de nenhum dos dois autores acima arrolados, todavia, em certo momento, mereceu uma grande atenção, que se refletiu na tradução de seu "Lehrbuch der Physikalischen Geographie" para o espanhol (onde recebeu sucessivas edições entre 1925 e 1940) e para o português em 1934. Achamos porém justo chamar a atenção para este livro, uma vez que em seu XI capítulo, intitulado "Geomorfologia", desenvolve uma abordagem processual até certo ponto moderna e traz para nosso meio, às p. 167,168 e 169 , uma crítica bastante pertinente ao paradigma davisiano, que entretanto parece ter tido pouco eco em nosso meio científico e acadêmico.

Este contexto evidencia que qualquer que tenha sido a alavanca propulsora da oposição ao paradigma davisiano, o resultado foi a emergência de novos conceitos e métodos de trabalho ,os quais desembocaram em dois 
acontecimentos que marcaram a década de vinte. Em 1924 é publicado, postumamente, "Die Morphologische Analyse. Ein Kapitel der physikalischen Geologie” e, em 1926, realiza-se o "Düsseldorfer Naturforschertag", do qual emerge em um ambiente de consenso geral o conjunto de proposições que valorizam o clima como elemento responsável por uma morfogênese diferencial em função do balanço das forças em ação (ECKERT et alii, 1927).

Walther Penck, que desapareceu aos 35 anos de idade, depois de percorrer vastos trechos da América e Eurásia, vai emergir, em função da natureza de sua obra, como o principal opositor de Davis e assumir, para alguns, na corrente de pensamento geomorfológico alemã um papel equivalente de fundador, como the atribui LEUZINGER (1948).

A rigor sua obra deve ser encarada como elo importante no pensamento científico moderno em língua alemã e alternativa paradigmática significativa, em função da postura davisiana. No sentido da formalização teórica talvez seja até sensivelmente superior a Davis, embora tenha sido muito prejudicada face às circunstâncias em que foi escrita, motivo pelo qual sua compreensão é difícil mesmo para os alemães, dado o estilo em que está vazada. (W. Penck já estava profundamente debilitado em função do câncer, do qual veio a falecer, quando redigiu este trabalho). Todavia a tradução para o inglês em 1953 diminuiu, em parte, essas deficiências, dado o resumo, o glossário e as notas que enriqueceram e facilitaram a leitura deste texto.

O âmago de sua proposta parece-nos contida, em sua essência, na passagem do item 1 para o 2 e no decorrer deste, no capítulo primeiro de sua obra: "Which physical methods are concerned, and at what stage in the morphological investigation they not only may, but must, be applied follows from the nature of the three elements which together form the substance of morphology.

2. Basis, Nature and Aim of Morphological Analysis

These three elements are:

1. the exogenetic processes

2. the endogenetic processes

3 . the products due to both, which may here be called the actual morphological features", conforme pode se ler às p. 3 e 4 da versão inglesa de 1953. Igual- mente digna de transcrição parece-nos a caracterização que ele faz do terceiro conjunto de elementos acima mencionado:

"All the actual morphological features can, like the exogenetic processes, be directly observed, and are thus an object of inductive research. However, their limits must be extended farmore widely than is customary. It is by no means enough to determine and to characterise the forms of denudation as they actually appear in their various combinations; the stratigraphical relations of the correlated strata formed simultaneously, are of just as great importance. Their thicknesse and the way in which they are deposited on the top of one another, how they are connected with their surroundings in the vertical and in the horizontal direction, their stratification and specially their facies, reflect both the type of development in the associated area of denudation, and its duration, and they supplement in essential points the history recorded there. The position of this record in the geological time sequence depends entirely upon investigation of the correlated strata and their fossil content. As a rule far too little weight is given to working on this stratigraphical material. Because of this, our knowledge about the actual morphological features is correspondingly scanty. True, we must take into account that these are not, like denudation, for instance, subject to one uniform set of laws; but that they are peculiar to each individual part of the crust which will have undergone a special development of its own. They are individual in their character" (1953, p. 5).

Concebida pelo seu autor com o objetivo de, utilizando-se da geomorfologia, atingir a geologia e contribuir para a elucidação dos movimentos crustais, a obra acabou por oferecer um paradigma alternativo e contribuir grandemente para o avanço da geomorfologia, principalmente através da formalização do conceito de depósito correlativo.

W. Penck foi extremamente criticado, não só pelo próprio Davis mas, principalmente, pelos seguidores deste e uma boa exposição dessas objeções está claramente formulada por LEUZINGER (1948). Todavia a publicação em 1953 da versão inglesa de seu trabalho iniciou um processo de revisão conceitual e teve o mérito de levar alguns autores norte-americanos interessados no es- 
tudo de vertentes e processos a reverem suas opiniões em relação à proposta penckiana. Vale a pena a esse propósito remeter-se o leitor para CARSON \& KIRBY (1972) p. 16.

Na U.R.S.S a proposta penckiana foi retomada por GERASSIMOV $(1946,1968)$ e utilizada como base conceitual para a análise morfoestrutural e sua correspondente cartografia geomorfológica. A divulgação desta abordagem fora da União Soviética tem sido relativamente pequena, dada as barreiras lingüísticas, todavia seus conceitos fundamentais encontram-se expostos através do artigo de MESCERJAKOV (1968), sendo as melhores exposições do método aquelas feitas por BASENINA \& TRESCOV (1972) e BASENINA et alli (1976).

Quanto ao Düsseldorfer Naturforschertag, realizado no contexto do $86^{\circ}$ Simpósio da Gesellschaft deutscher Naturforscher und Aerzte, marca o advento dos estudos ditos de geomorfologia climática e climatogenética, de cujos resultados WILHELMY (1974, 1975) apresentou um balanço bastante completo. Entre os resultados desta reunião deve-se destacar principalmente o esforço de Passarge para incorporar as condicionantes climáticas no estudo das formas de relevo. Uma interessante revisão dos debates então travados e dos avanços subseqüentes foi feita recentemente por BUSCHE \& HAGEDORN (1980), no decorrer do Primeiro Simpósio Teuto-britânico sobre Geomorfologia, desenvolvido em Würzburg, de 24 a 29 de setembro de 1979 e que originou o Supplementband 36 do Zeitschrift für Geomorphologie.

A linha de abordagem que emerge de Düsseldorf consolidou-se através das pesquisas de BÜDEL (1948, 1957, 1963, 1969 e 1971), cujos estudos levaram a uma ordenação dos conjuntos morfológicos de origem climática em zonas e andares, produzidos pela interação das variáveis epeirogênicas, climáticas, petrográficas e fitogeográficas.

Aos nomes de Büdel e Whilelmy, devemos ajuntar, pelo menos, os de LOUIS (1957, 1968), MORTENSEN (1943/1944) e MACHATSCHECK (1955) na consolidação da abordagem climática e climatogenética, que, de maneira muito apropriada incorporou as noções de depósitos correlativos na análise das formas.

As propostas conceituais voltadas para a paisagem ("Landschaft"), provavelmente de interesse maior para a geografia como um todo, do que para a própria geomorfologia e que já haviam recebido a atenção de Passarge, evoluem e se consolidam nos estudos de geoecologia e ordenação ambiental do espaço ("naturräumliche Gliederung"). Neste setor devemos ressaltar o papel de TROLL (1932, 1939, 1959, 1966), o qual continua nesta linha de pesquisa, que vem a se aprofundar e enriquecer nos últimos anos principalmente através das contribuições de BARTHEL (1968), HAASE (1964, 1967, 1973), KLINK (1966, 1972), MARTENS (1968), LESER $(1971,1973)$, NEUMEISTER (1977), NEEF $(1967,1970)$ e RICHTER (1968). Devemos, aliás, registrar que esta abordagem está em grande parte apoiada na teoria sistêmica, na base da qual encontramos os conceitos de BERTALANFFY (1942, 1965).

A cartografia geomorfológica recebe ênfase especial, principalmente no segundo pós-guerra, adquirindo características próprias em cada país do leste europeu e emergindo como método fundamental para a análise do relevo. Devemos destacar neste sentido a contribuição que se originou dos esforços desenvolvidos na Polônia, Tchecoslováquia e U.R.S.S. (KLIMASZEWSKI, 1963; DEMEK, 1976; BASENINA \& TRESCOV, 1972).

A República Federal Alemã iniciou em 1976 seu projeto de mapeamento geomorfológico detalhado (BARSCH, 1976, 1980) sob o patrocínio da Deutsche Forschungsgemeinschaft, enquanto na República Democrática Alemã esta tarefa já foi iniciada há mais tempo (KUGLER, 1976b). Devemos aliás salientar o papel deste geomorfólogo nos aspectos teóricos conceituais desta problemática (KUGLER, 1975 e 1976a).

É ainda importante registrar que, de certa forma a II Guerra Mundial não rompeu a tradição da geomorfologia centro e leste européia nos seus aspectos básicos. Pelo contrário, o apoio que os regimes socialistas deram à pesquisa beneficiou-a sobremaneira $\mathrm{e}$ o avanço do mapeamento geomorfológico é um fato que salta às vistas. Por outro lado ela vai assumindo um papel cada vez mais significativo no planejamento regional, o que acaba se refletindo na própria classificação formal da disciplina que torna-se nitidamente geográfiç e voltada para a sociedade como um todo, superando as artificiais dicotomias ainda bastante arraigadas na linhagem conceitual de língua inglesa. 


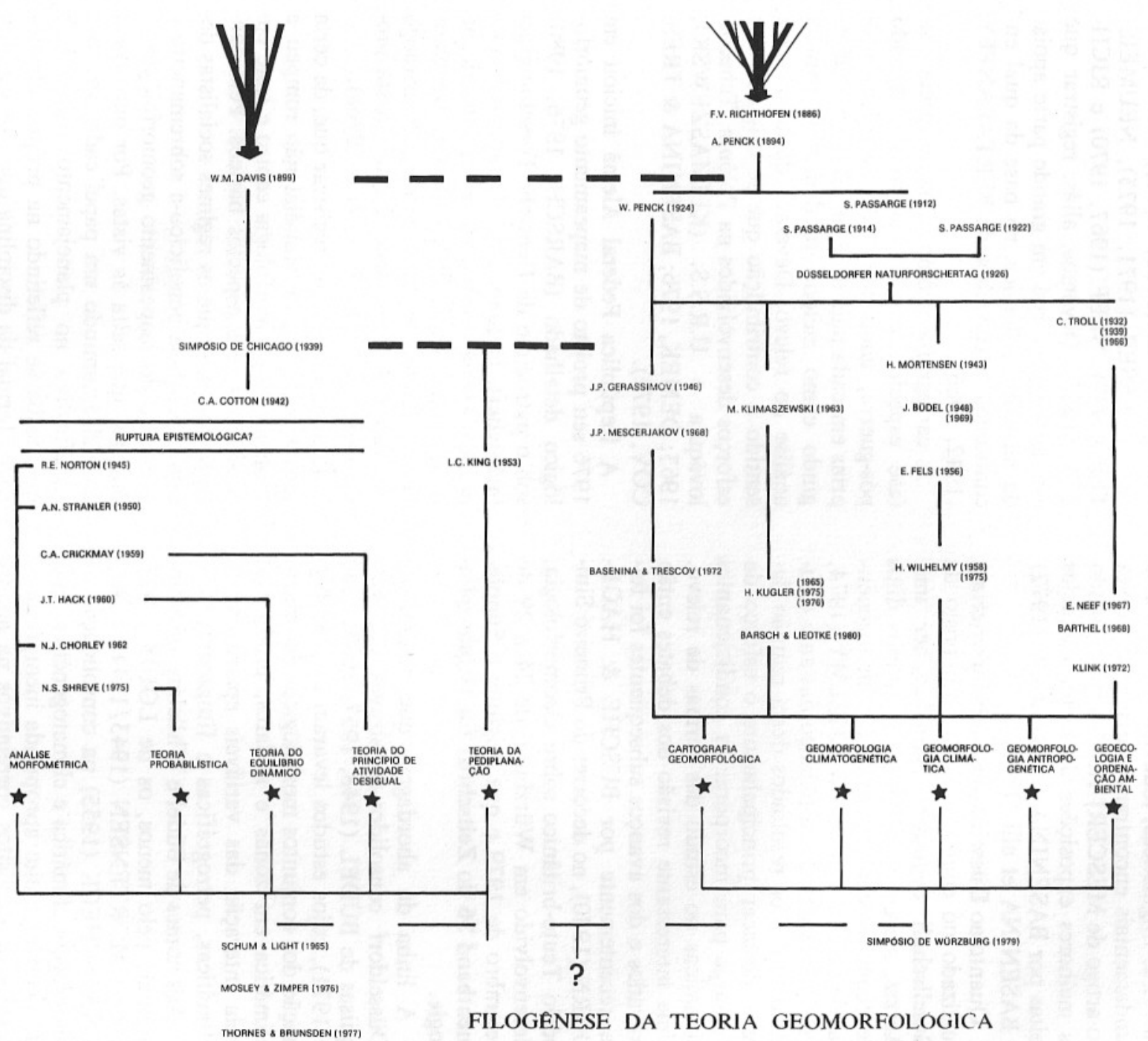




\section{SINTESE COMPARATIVA}

Uma revisão crítica da evolução dos principais conceitos, sistemas de conceitos e paradigmas geomorfológicos pode ser feita a partir do esquema em anexo. Em primeiro lugar, todavia, devemos chamar a atenção para o elevado grau de simplificação que este quadro traz consigo. Ele tem a intenção de mostrar, de maneira esquemática, como, a partir de duas concepções diferentes, evoluiu o sistema conceitual angloamericano e o alemão.

De início queremos ressaltar que a ordenação dos autores foi encarada não por eles em si, mas no que eles traziam consigo e que poderia ser tomado como fato representativo em um contexto global de cada corrente. Desta forma, e isto é válido principalmente para o conjunto alemão, aparentemente cometeram-se algumas injustiças, na medida que no quadro aparecem alguns nomes que poderiam ser vistos como "menores", quando comparados com outros que indiscutivelmente seriam "maiores".

A justificação para essa situação emerge, em parte, de uma característica básica da corrente alemã. Ela é marcada por um aspecto mais coletivo, englobando um número muito maior de nomes, de envergadura mais ou menos equivalente, porém em um contexto de interesses e proposições diferenciadas.

Já a corrente anglo-americana é mais marcada por nomes de grande destaque, particularmente nas primeiras décadas do século atual, apresentando um aspecto mais individualista. O exemplo mais típico é o próprio Davis, que detém uma primazia quase sem contestação por longo lapso de tempo.

Em segundo lugar é fundamental insistir que este quadro resultou de uma interpretação, face ao material que dispúnhamos, o qual, inclusive, é rico em opiniões que nos contraditam. Neste sentido ele é uma opção. Poderíamos até lembrar pelo menos dois autores de renome que, evidentemente, fariam reparos a esta postura: um deles é ENGELN (1942) p. 6 e outro é BULLA (1956) p. 167. Ambos, provavelmente, discordariam da posição que atribuímos a $\mathrm{S}$. Passarge. $\mathrm{O}$ primeiro lembraria que $\mathrm{S}$. Passarge, assim como J. Walther teriam aceitado, em um certo momento, a postura davisiana. Ao que responderíamos, que o mais significativo do ponto de vista conceitual, especialmente no caso de Passarge, emerge de uma postura diferente, eventualmente resultante de uma revisão, pois sua produção está longe de poder ser rotulada de davisiana. Já Bulla discordaria em função de uma interpretação diferente no processo de edificação dialética da geosfera. É uma objeção, sem dúvida alguma de maior peso, que deve porém ser julgada em função do conceito de harmonia, o qual permeabilizou boa parte da geografia alemã em certo período e que parece-nos hoje claramente superado. Somos de opinião que S. Passarge, pelo que introduziu ou formalizou em termos conceituais e propostas metodológicas, deve merecer uma posição de destaque na cadeia evolutiva de posturas assumidas no contexto da geografia alemã.

Um terceiro aspecto a lembrar é que as entradas no sistema de análise proposto correspondem, por assim dizer, a fluxos que se dispersam em direção à origem. Isto é, se a análise considerasse um lapso de tempo maior, remontando aos precursores, haveria uma abertura em leque para o passado, com muitos outros pontos de superposição e interferência. Nesse sentido, Davis, v. Richthofen e A. Penck são, de maneira figurada, catalizadores do passado que, através de formalizações mais adequadas lançaram as bases dos conceitos, os quais progressivamente se aprimoraram e chegaram até nós, constituindo o conteúdo e as formas de abordagem presentes da geomorfologia. Esta figura de linguagem, aliás, é mais pertinente para a corrente alemã.

Outro fato a registrar é que, embora graficamente o encadeamento dos conceitos sugira evolução paralela, sem pontos de contato, isto não corresponde à realidade. Procuramos superar este aspecto através de traços interrompidos, registrando as interferências mútuas, cujos resultados, aliás, podem ser facilmente identificáveis na produção científica das duas correntes. No quadro apresentado, a interferência mais nítida é expressa através da proposta de L. C. King, embora pareça-nos legítimo uma expectativa de renovação muito importante, cujos resultados são de difícil previsão, a partir da fase de revisão do lado anglo-americano, que se inicia de maneira mais clara com Schumm \& Lichty e da realização do Simpósio de Würtzburg. Neste sentido, aliás, o quadro sugere, inclusive, uma possível tendência à 
aproximação e produção de resultados que se baseiam nos dois conjuntos conceituais aqui explorados.

Em nosso meio, inclusive, provavelmente fruto do Congresso de Geografia do Rio de Janeiro (1956) - um dos inúmeros momentos de interferências entre as duas correntes - já se esboçou uma tendência conceitual neste sentido, com a incorporação das diferentes posturas em u'a proposição que, salvo melhor juízo, parece dar a tônica nos postulados de raízes germânicas. Tratase da proposição feita por AB'SABER (1969) e que, de maneira consciente ou inconsciente se reflete no grosso da produção geomorfológica que emana do Departamento de Geografia da F.F.L.C.H. da U.S.P. e que a nosso ver é a mais séria contribuição brasileira ao nível da teoria geomorfológica, superando em parte os esforços feitos por outros autores também vinculados à contextos estranhos ou pelo menos periféricos em relação às áreas centrais de produção do construto geomorfológico.

Voltando ao quadro de referência em questão, é igualmente digno de registro que se houve ruptura epistemológica significativa nos sistemas conceituais em análise, isto teria ocorrido do lado anglo-americano. Todavia devemos lembrar que as tendências recentes na reflexão científica (MOSLEY \& ZIMPER, 1976; THORNES \& BRUNSDEN, 1977), parecem procurar harmonizar este quadro, assumindo uma postura crítica baseada em uma valorização das variáveis significativas do processo geomorfológico segundo um sistema referencial têmporoespacial (SCHUMM \& LICHTY, 1965).

A figura em apreço evidencia-nos, também, que a geomorfologia alemã ainda está vinculada a certas propostas kantianas, via Hettner, embora seja irrecusável a vinculação naturalista originária particularmente de Humboldt. Isto se expressa claramente nos resultados finais de cada fluxo de idéias, que não se resume por uma teoria, mas sim por um sistema de conceitos ao nível da generalização empírica, segundo as propostas de Hempel, como já registramos ao citar KITTS (1970), tratando da teoria da geologia. Ao lado disto a principal contribuição ao nível do método, provavelmente, é a da cartografia geomorfológica. $\mathrm{O}$ aspecto positivo desta postura é, sem dúvida alguma, sua integração bastante estreita em um qua- dro de referências claramente geográficas, através da geoecologia e da ordenação ambiental (naturräumliche Gliederung). É provável mesmo que esta direção tenha sido estimulada através da análise espacial dos processos geoecológicos, segundo uma ótica marxista, mais facilmente identificável nas propostas oriundas dos países socialistas. De qualquer forma, todavia, suas bases já estavam lançadas na própria Alemanha, anteriormente à II Guerra Mundial e a incorporação da análise sistêmica contribuiu para aprofundar, ainda mais, suas concepções.

Já no caso anglo-americano a postura é diferente, na medida que já em sua origem assume, através de Davis, uma posição bergsoniana em um quadro de referências teorizantes. O resultado será um isolamento da geomorfologia em relação ao resto da geografia, particularmente nítido no período mais aceso da disputa entre possibilistas e deterministas. Nesta fase o grosso dos geógrafos norte-americanos refugia-se nas ciências sociais e os que militam na geomorfologia acabam se orientando muito mais em função de perspectivas geológicas e hidrológicas, como bem lembrou BURTON (1963). Por outro lado a geomorfologia davisiana, embora em certos aspectos não seja contestada hoje em dia por alguns grupos, também acabou privilegiando o único e no momento que o excepcionalismo foi maciçamente atacado nos USA, através da chamada revolução quantitativa, seu paradigma de apoio foi, da mesma forma, violentamente contestado, emergindo então as teorias alternativas. Uma particularidade da geomorfologia de língua inglesa é que desde o início, mesmo segundo Hempel, ela trabalha com conjuntos de conceitos próximos ou já ao nível da teoria.

Essa diversidade de caráter da geomorfologia anglo-americana e alemã pode ser facilmente explorada a partir de autores que interessam tanto ao campo da geografia como da geologia (SCHAEFER, 1953; ACKERMAN, 1963; BURTON, 1963; DAVIES, 1966; PATTINSON, 1964; MIKESELL, 1969; KITTS, 1970; BUBNOFF, 1954).

O resultado dessa evolução diferenciada é que principalmente do lado anglofônico localizam-se as teorias e os métodos de análise quantitativas como instrumentos de pesquisa, ao passo que do lado germanofônico encontramos basicamente um sistema de 
classificação conceitual do objeto da geomorfologia expresso em suas divisões formais, um método de pesquisa que valoriza principalmente a cartografia geomorfológica e uma disciplina que incorpora parte do conteúdo formal de seu campo em um sistema de análise ambiental voltado para o homem e que surge como instrumento de articulação teórica com a geografia.

Essa constatação é, obviamente, uma simplificação. É uma busca de aspectos que permitam caracterizar uma corrente face à outra. É evidente, por exemplo, que também na Alemanha se busca quantificar; é ali, aliás, que veio à luz a "Theoretical Geomorphology”, SCHEIDEGGER (1961). Todavia isto não é o mais significativo da produção alemã, assim como a cartografia geomorfológica também não dá a tônica na corrente anglo-americana.

Uma análise mais abrangente das duas tendências acima registradas permite-nos retomar alguns pontos já assinalados, que julgamos, porém, importante ressaltar. Um fato fundamental é que ambas evoluíram a partir de pontos de vistas bastante diferentes e embora se fale hoje em convergência a nível internacional do conhecimento, as duas tendências ainda se apresentam razoavelmente diferenciadas.

Dado importante é que ambas evoluíram freqüientemente procurando responder ou superar objeções que emergiram do outro modo de pensar ,independente do motivo que justificava a busca de uma identidade em relação à outra proposta. Neste sentido pode-se falar, de maneira figurada, que a geomorfologia alemã das primeiras décadas do século XX constituiu-se em um dos aspectos da resistência prussiana ao desafio americano.

Fica muito claro também que a reformulação do pensamento geomorfológico angloamericano, no decorrer deste século, foi muito mais profunda do que se registrou na geomorfologia alemã. Neste sentido é mais fácil argumentar-se em favor de uma ruptura epistemológica, pelo menos para certa fase, no caso do pensamento em língua inglesa. No caso alemão parece que fica melhor caracterizada uma refinação progressiva de conceitos, através de uma continuidade subjacente que dá a tônica ao conjunto das propostas. Isto provavelmente se vincula ao fato, já mencionado, de que a geomorfologia anglo-americana praticamente emerge para o século XX através de uma postura teorizante, que posteriormente é, inclusive, internamente contestada, ao passo que a geomorfologia alemã, desde o início, valoriza sobremaneira a observação e o empírico, o que é válido igualmente para a própria geologia alemã (BUBNOFF, 1954). Parecenos significativo que enquanto uma tenha como ponto de partida um trabalho intitulado "The geographical cycle", a outra possua como referência de apoio inicial um trabalho cujo título é "Führer für Forschungsreisende" (Guia para pesquisadores de campo"), trazendo como subtítulo "Anleitung zur Beobachtungen über Gegenstände der physischen Geographie und Geologie" (Introdução às observações sobre os fatos da geografia física e geologia).

Outro fato a ser frisado é que o impacto do estruturalismo e da teoria de sistemas nas duas correntes teve resultados bastante diferentes. Se é verdade que em ambos os casos valorizaram-se contextos espaciais, do lado alemão emerge reforçada a visão integradora de ciências naturais com tônica substancial nas análises geoecológicas processuais, ao passo que a perspectiva angloamericana incorpora a mudança mais com o sentido de ruptura com as abordagens historicistas. Até certo ponto representa um esforço dos pesquisadores de língua inglesa para absorver a crítica de SCHAEFFER (1953) e superar o que havia ainda de excepcionalismo na geomorfologia por eles produzida.

O esquema gráfico evidencia, ainda, a diversidade da posição de W. Penck e de W. M. Davis no contexto das duas correntes de pensamento; enquanto o segundo é o principal ponto de referência da geomorfologia de língua inglesa, o primeiro é um dos grandes entre muitos geomorfólogos de língua alemã. À esse propósito vale a pena lembrar que, em grande parte, as objeções que Penck reptou a Davis não podem ser tomadas como representativas de todo o conjunto alemão, na medida que o próprio Penck compartilhava, embora através de outra fonte, algumas nições básicas com a teoria davisiana; uma lelas, inclusive, é a do aplainamento do relevo, que A. Penck também conceituara, trabalhando isoladamente, sem conhecer ainda a proposta norte-americana e publicando os resultados um 
ano após Davis ter divulgado o princípio de peneplanação (PENCK, 1953) p. 302, 18 , nota dos tradutores.

Encerrando estas observações queremos registrar que, embora passível de reparos, essa visão bipolarizada da evolução da teoria geomorfológica permite uma explicação bastante satisfatória para certas posições assumidas por diferentes autores no decorrer do tempo, mesmo quando estes não se integram claramente em cada uma das duas correntes identificadas. Através desse sistema de referências fica-nos mais segura a crítica geomorfológica.

Este esquema, por outro lado, origina-se de um esforço no sentido de superar-se uma situação incômoda, oriunda de uma história que, no caso brasileiro, valorizou em boa parte uma perspectiva tomada a partir da periferia em relação aos núcleos de geração principal da teoria geomorfológica. Isto se reflete inclusive na possibilidade de eliminação da visão antinômica representada pela presença da geomorfologia dita estrutural, que corresponde principalmente a um rótulo de reação, cunhado em área periférica ao centro gerador da geomorfologia de língua inglesa, como já registrou REYNAUD
(1971) p. 11, embora se referindo a um contexto diferente do aqui proposto. Nesse sentido o arcabouço conceitual apresentado, se não é completo, pode ser encarado, pelo menos como mais satisfatório.

Finalmente é importante frisar que a partir de uma perspectiva têmporo-espacial em relação ao objeto de estudo da geomorfologia, os conceitos encadeados no gráfico de maneira aparentemente paralela, podem ser articulados de forma harmoniosa, integrando-se a visão cíclica de Davis a King, com a postura de Büdel face à Geomorfologia climatogenética, enquanto as análises em lapsos de tempos mais curtos permitem associar, por exemplo, a teoria do equilíbrio dinâmico com as posturas da geomorfologia climática e da fisiologia da paisagem, emergindo as técnicas quantitativas e a cartografia geomorfológica, como os instrumentos valorizados pelos diferentes autores para expressar suas posições face à realidade abordada. Em outras palavras, da diversidade das posturas no decorrer do tempo, surge uma unidade conceitual que permite definir claramente o campo, os níveis de tratamento e os métodos de investigação da geomorfologia.

\section{REFERÊNCIAS BIBLIOGRÁFICAS}

ABREU, A. A. de - 1978 - Considerações a respeito de uma epistemologia da geomorfologia. Boletim Paulista de Geografia, São Paulo, (55):125-135, nov.

$\perp 1980$ - Surell e as leis da morfologia fluvial. São José do Rio Preto, UNESP, IBILCE. 13p. (Craton \& Intracraton: escritos e documentos, 7)

AB'SÁBER, A. N. - Um conceito de geomorfologia a serviço das pesquisas sobre o Quaternário. São Paulo, Universidade, Instituto de Geografia. 23p. (Geomorfologia, 18).

AKERMANN, E. A. - 1963 - Where is a research frontier? Annals of the Association of American Geographers, Washington, D.C., 53(4):429-440, Dec.

BARSCH, D. - 1976 - Das GMK-Schwerpunktprogramm der DFG: Geomorphologische Detailkartierung in der Bundesrepublik. Zeitschrift für Geomorphologie N.F., Berlin, 20 (4):488-498, Dez.
BARSCH, D. \& LIEDTKE, H. - 1980 - Principles, scientific value and practical applicability of the geomorphological map of the Federal Republic of Germany at the scale of 1:25 000 (GMK25) and 1:100 000 (GMK100). Zeitschrift fur Geomorphologie N.F., Berlin. p. 296-313. Supplementband, 36.

BARTHEL, H. - 1968 - Landschaftsforschung: Beiträge zur Theorie und Anwendung. Leipzig.

BASENINA, N. V. \& TRESCOV, A. A. - 1972 - Geomorphologische Kartierung des Gebirgsreliefs im Masstab 1:200 000 auf Grund einer Morphostrukturanalyse. Zeitschrift für Geomorphologie N.F., Berlin, 16(2):125-138, Jun.

- et alii - 1976 - Methoden zur Analyse der Morphostrukturen auf Grund vorliegender Karten und Luftbildaufnahmen. In: DEMEK, J. Handbuch der geomorphogischen Detailkartierung. Viena, Ferdinand Hirt. p. 131-151. 
BERTALANFFY, L. von - 1942 - Treoretische Biologie. Berlin.

- -1965 - Die Biophysik offener Systeme. Naturwissenschaftliche Rundschau, Stuttgart, 18:467-469.

- -1973 - Teoria geral dos sistemas; tradução de Francisco M. Guimarães. Petrópolis, Vozes.

BIROT, P. - 1960 - Le cycle d'érosion sous les différents climats. Rio de Janeiro. 137p. (Brasil. Universidade. Faculdade Nacional de Filosofia. Centro de Pesquisas de Geografia do Brasil. Curso de altos estudos geográficos, 1).

BUBNOFF, S. von - 1954 - Grundprobleme der Geologie. Berlin, Akademie Verlag.

BUDEL, J. - 1948 - Das System der klimatischen Morphologie. Deutscher Geographentag, München, 27(4):65-100.

- -1957 - Die Doppelten Einebnungsflaechen in den feuchten Troppen. Zeitschrift für Geomorphologie N.F., Berlin, 1(2): 201-228.

- -1963 - Klima-genetische Geomoy phologie. Geographische Rundschau, Braunschweig, 15(7):269-285.

- -1969 - Das System der klimageenetischen Geomorphologie. Erdkunde, Bonn, 23(3):165-183.

BUDEL, J. - 1971 - Das naturliche system der Geomorphologie... Wurzburg, Im Selbstverlag des Geographischen Instituts der Universitat Wurzburg in Verbindung mit der Geographischen Gesellschaft Wurzburg. 152p. (Wurzburg geographische Arbeiten, 34)

BULLA, B. - 1956 - Gedanken ueber die Natur, die Grundeigenschaften und die Gesetze der Reliefentwinklung In: CONGRES INTERNATIONAL DE GEOGRAPHIE, $18 .^{\circ}$, Rio de Janeiro. Comptes Rendus... Rio de Janeiro, Conselho Nacional de Geografia, p. $166-174$

BURTON, I. - 1963 - The quantitative revolution and theoretical geography. The Canadian Geographer, Ottawa, 7:151-162.

BUSCHE, D. \& HAGEDORN, H. - $1980-$ Landform development in warm deserts the central Sahara Exemple. Zeitschrift für Geomorphologie N. F., Berlin. p. 123-139. Supplementband, 36.

CARSON, M. A. \& KIRBY, M. J. - $1972-$ Hillslope: form and process. London, Cambridge University Press.

CHORLEY, R. J. - 1962 - Geomorphology and general systems theory. Washington, D.C. 10 p. (Geological Survey professional paper, 500-B).

- et alii - 1964 - The history of the study of landforms... or the development of geomorphology. London, Methuen. v. 1.

CHORLEY, R.J. - 1972 - Spatial analysis in geomorphology. London, Methuen.

\& HAGGETT, P. - 1974 - Modelos integrados em geografia; trad. Arnaldo Vi- riato de Medeiros. Rio de Janeiro, Livros Técnicos e Científicos Editora, São Paulo, EDUSP. 221p. (Modelos em geografia).

- 1975 - Modelos físicos e de informação em geografia; trad. Arnaldo Viriato de Medeiros. São Paulo, EDUSP, Rio de Janeiro, Livros Técnicos e Científicos Editora. 260p. (Modelos em geografia).

COTTON, C.A. - 1942 - Climatic accidents in landscape-making; a sequel to "Landscape as developed by the processes of normal ero. sion", London, Whitcombe \& Tombs. 354p.

CRICKMAY, C.H. - 1959 - A preliminary inquiry into the formulation and applicability of the geological principle of uniformity. Calgary, Evelyn de Mille Books. 53p.

- -1960 - Lateral activity in a river of northwestern Canada. Journal of Geology, Chicago, Ill., 68(4):377-391.

DAVIS, W.M. - 1899 - The Geographical Cycle Journal, London, 14(5):481-504.

DAVIES, W.K.D. - 1966 - Theory, science and geography. Tijdschrift voor Economische en Sociale Geographie, Rotterdam, 57(4):125-130, Jul./Aug.

DEMEK, J. - 1976 - Handbuch der geomorphologischen Detailkartierung. Viena, Ferdinand Hirt.

ECKERT, M. et alii - 1927 - Düsseldorfer geographischer Vortraege und Eroerterungen. Breslau, Ferdinand Hirt.

ENGELN, O.D. von - 1940 - Symposium: Walther Penck's contribution of American logy. Annals of the Association of American Geographers, Washington, D.C., 30(4):219284.

- -1942 - Geomorphology: systematic and regional. New York, The Macmillan. $655 \mathrm{p}$.

ENZMANN, R.D. - 1968 - Geomorphology: expanded theory. In: FAIRBRIDGE, R.W. The Encyclopedia of geomorphology. New York, Reinhold. p.404-410. (Encyclopedia of earth sciences series, vol. 3).

GERASSIMOV, I.P. - 1946 - Essai d'interprétation geomorphologique du schéme général de la structure geologique de l'URSS. Moscou. (Problèmes de Geographie Physique, v. 12).

- \& MESCHERIKOV, J.A. - 1968 Morphostructure. In: FAIRBRIDGE, R.W. The Encyclopedia of geomorphology. New York, Reinhold. p.731-732. (Encyclopedia of earth sciences, vol. 3)

GRAF, W. et alii - $1980-$ Geographic Geomorphology in the eighties. The Professional Geographer, Washington, D.C., 32(3): 279-284.

GREGORY, K.J. \& WALLING, D.E. - 1973 Drainage basin: form and processes... London, Edward Arnold. 
GUNTHER, S. - 1934 - Geografia física; trad. Lyon Davidovich. Rio de Janeiro, Atlântica.

HAASE, G. - 1964 - Landschaftsokologische Detailuntersuchung und naturraumliche Gliederung. Petermanns Geographische Mitteilungen, Gotha, 108(1-2):8-30.

- -1967 - Zur Methodik grossmasstabiger landschaftsoekologischer und naturraeumilicher Erdkundung. Wiss. Abj. der Geogr. Gesellschaft der DDR, 5:35-128.

- - 1973 - Zur Ausgliederung von Raumheiten der chorischen und regionischen Dimension. Petermanns Geographische Mitteilungen, Gotha, 117:81-90.

HACK, J.T. - 1960 - Interpretation of erosional topography in humid/temperate regions. American Journal of Science, New Haven, Conn., 258-A:80-97. (Bradley volume).

HAGEDORN, H. \& THOMAS, M. - $1980-$ Perspectives in geomorphology'. Zeitschrift

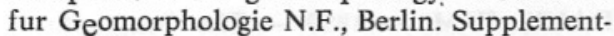
band, 36 .

HETTNER, A. - 1921 - Die Oberflaechenformen des Festlandes. Leipzig, B.G. Teubner.

- 1927 - Die Geographie. Ihre Geschichte, ihr Wesen und ihre Methoden. Breslau, Ferdnand Hirt.

HORTON, R.E. - 1945 - Erosional development of streams and their drainage basins: hydrophysical approach to quantitative morphology. Bulletin of the Geological Society of America, Washington, D.C., 56(1):275-370.

KING, L.C. - 1953 - Canons of landscape evolution. Bulletin of the Geological Society of America. Washington, D.C., 64(7):721-732.

- 1956 - A geomorfologia do Brasil oriental. Revista Brasileira de Geografia, Rio de Janeiro, 18(2):147-265.

Edinburgh, Oliver.

KITTS, D. - 1970 - Teoria de la geologia. In: ALBRITTON, C.C. Filosofia de la geologia. México, Continental.

KLINK, H.J. - 1966 - Naturräumliche Gliederung des Ith-Hils-Berglandes: Art und Anordnung der Physiotope un Okotope. Bad Godesberg, Bundesanstalt für Landeskunde, und Raumforschung. 257p. (Forschungen zur deutschen Landeskunde, v. 159).

- 1972 - Geooekologie und naturräumliche Gliederung. Grundlagen der Umweltforschung. Geographische Rundschau, Braunschweig, 24(1):7-19.

KLIMASZEWSKI, M. - 1963 - Problems of geomorphological mapping. Varsóvia, Academia Polonesa de Ciências. (Estudo geográfico, 46).

KUGLER, H. - 1975 - Grundlagen und Regeln der kartographischen Formulierung geographischer Aussagen in ihrer Anwendung auf geomorphologische Karten. Petermanns Gographische Mitteilungen, Gotha, 119(2):145159.
KUGLER, H. - 1976a - Kartographish_semiotische Prinzipien und ihre Anwendung aug geomorphologische Karten. Petermanns Geographische Mitteilungen, Gotha, 120(1):65-78.

- - 1976b - Zur Aufgabe der geomorphologischen Forschung und Kartierung in der DDR. Petermanns Geographische Mitteilungen, Gotha, 120(2):154-160.

KUHN, T.S. - 1970 - The structure of scientific revolutions. In: INTERNATIONAL ENCYCLOPEDIA OF UNITED STATES. 2.ed. Chicago, Ill., The University of Chicago Press. v. 2 n. 2.

LEIGHLY, J. - 1940 - Comments in: Walther Penck's contribution to geomorphology symposium (1939). Annals of the Association of American Geographers, Washington, D.C. 30(4):223-227.

LEUZINGER, V.R. - 1948 - Controvérsias geomorfológicas. Rio de Janeiro, Jornal do Comércio.

LESER, H. - 1971 - Landschafsoekologische Grundlagenforchung in Trockengebieten. Dargestellt an Beispielen aus der Kalahari und ihren Randlandschaften. Erdkunde, Bonn., 25(3):209-223.

- 1973 - Zum Konzept einer Angewandten Physischen Geographie. Geographische Zeitschrift, Leipzig, 61(1):36-46.

LOUIS, H. - 1957 - Rumpflaechenproblem, Erosionszyklus und Klimamorphologie. In: Geomorphologische Studien, MachatschekEestschrift, p.9-26.

- - 1961 - Ueber Weiterentwiklungen in den Grundvorstellungen der Geomorphologie. Zeitschrift für Geomorphologie, N.F., Berlin, 5(3):194-210.

- - 1968 - Allgemeine Geomorphologie. 2nd. ed. Berlin, Walter de Gruyter. 355p.

MACHATSCHEK, F. - 1955 - Das Relief der Erde; Versuch einer regionalen Morphologie der Erdoberfläche. Berlin, Gebrüder Borntraeger. $2 \mathrm{v}$.

MARTENS, R. - 1968 - Quantitative Untersuchungen zur Gẹstalt, zum Gefüge und Haushalt der Naturlandschaft (Imoleser Subapennin). Hamburg, Im Selbstverlag des Instituts fur Geographie und Wirtschaftsgeographie der Universitat Hamburg. 251p. (Hamburger geographische Studien, n. 21)

MARTONNE, L.E.E. de - 1950 - Traité de geographie physique. 9.ed. Paris, Armand Colin. $2 \mathrm{v}$.

MESCERJAKOV, J.P. - 1968 - Les concepts de morphostructure et de morphosculture: un nouvel instrument de l'analyse geomorphologique. Annales de Geographie, Paris, 77(423): 538-552.

MIKESELL, M.W. - 1969 - The borderlands of geography as a social science. In: SHERIF, M. \& SHERIF, C.W. Interdisciplinary relationships in the social sciences. Chicago, Aldine. 
MONTEIRO, C.A.F. - 1980 - A geografia no Brasil (1934-1977): avaliação e tendências. São Paulo, Universidade, Instituto de Geografia. 155p.

MORTENSEN, H. - 1943/1944 - Sechzig Jahre moderne geographische Morphologie. Goettingen, Abhandlungen der Akademie der Wissenschaften.

MOSLEY, M.P. \& ZIMPFER, G.L. - 1976 Explanation in geomorphology. Zeitschrift fur Geomorphologie, N.F., Berlin, 20(4):381-390.

MURAWSKI, H. - 1977 - Geologisches Wörterbuch, Stuttgart, Ferdinand Enke Verlag.

NEEF, E. - 1967 - Die theoretischen Grundlagen der Landschaftslehre. Leipzig, Gotha.

$-1970-\mathrm{Zu}$ einigen Fragen der vergleichenden Landschaftsoekologie. Geographische Zeitschrift, Leipzig, 58(3):161-175.

NEUMEISTER, H. - 1977 - Theoretische Fragen zur Landschaftsgenese. Geographische Berichte, Berlin, 22(1,82):20-32.

PASSARGE, S. - 1912 - Physiologische Morphologie. Hamburg, Friedericksen. 205p.

- 1919/1921 — Die Grundlagen der Landschaftskunde. Hamburg, L. Friederichsen. $2 \mathrm{v}$.

- -1922 - Die Landschaftsguertel der Erde. Breslau, Ferdnand Hirt.

- 1931 Geomorfologia; trad. espanhol J. Gómez de Llarena. Barcelona, Labor.

PATTINSON, W.D. - 1964 - The four traditions of Geography. The Journal of Geography, Chicago, Ill., 63(5):211-216.

PENCK, A. - 1894 - Morphologie der Erdoberfläche. Stuttgart, Engelhorn. 2v.

PENCK, W. - 1924 - Die Morphologische Analyse... Stuttgart, J. Engelhorn's Nachf. 283p.

- -1953 - Morphological analysis of land forms: a contribution to physical geology; trad. de Hella Czech. e Catherine C. Boswell. London, Macmillan. 429p.

QUELLE, O. - 1953 - 125 Jahre der Gesellschaft fur Erdkunde zu Berlin. Berlin, Selbstverlag der Gesellschaft fur Erdkunde zu Berlin. 35p.

REYNAUD, A. - 1971 - Épistemologie de la géomorphologie. Paris, Masson. 125p.

RICHTER, H. - 1968 - Beitrag zum Modell des Geokomplexes. In: BARTHEL, H. Landschaftsforchung: Beiträge zur Theorie und Anwendung. Leipzig.

RICHTHOFEN, F.F. von - 1886 - Führer für Forschungsreisende... Berlin, Robert Oppenheim. p.294-315.

SCHAEFFER, F.K. - 1953 - Excepcionalism in Geography: a methodological examination. Annals of the Association of American Geographers, Washington, D.C., 43(3):226-249.
SCHEIDEGGER, A.E. - 1961 - Theoretical geomorphology. Berlin, Springer Verlag. 327p.

SCHUMM, S.A. \& LICHTY, R.W. - 1965 Time, space and causality in geomorphology. American Journal of Science, New Haven, Conn., 263(2):110-119.

SHREVE, R.L. - 1975 - The probalistic-topologic approach to drainage-basin geomorphology. Geology, Boulder, Co., 3(9):527-529.

STRAHLER, A.N. - 1950 - Equilibrium theory of erosional slopes approached by frequency distribution analysis. American Journal of Science, New Haven, Conn., 248(8-9):673-696, 800-814.

- 1952 - Dynamic basis of geomorphology. Bulletin Geological Society of America, Washington, D.C. 63(9):923-938.

$-1954-$ Statistical analysis in geomorphic research. Journal of Geology, Chicago, Ill., 62(1):1-21.

STRATI-SAUER, G. - 1968 - Geomorphologie: Das Fischer Lexikon-Geographie. Frankfurt am Main, Fischer Buecherei.

TATHAM, G. - 1951 - Geography in the nineteenth century. In: TAYLOR, Griffith Geography in the twentieth century. London, Methuen. p.28-69.

THORNES, J.B. \& BRUNDSDEN, D. - $1977-$ Geomorphology \& time. New York, Wiley. 208p.

TRICART, J. - 1965 - Principes et méthodes de la geomorphologie. Paris, Masson. 496p.

TROLL, C. - 1932 - Die Landschaftsguertel der tropischen Anden. In: Inhandl. 24Dt. Geographentag zu Danzig. p.263-270.

gische Bodenforschung. Zeitschrift der Gesellschaft für Erdkunde zu Berlin. p.241-298.

- -1959 - Die tropischen Gebirge: Ihre dreidimensionale klimatische und pflanzengeographische Zonierung. Bonn, Ferdinand Duemmlers Verlag.

- - 1966 - Landschaftsoekologie als geographisch-synotische Naturbetrachtung. In: Oekologische Landschaftsforschung und vergleichende Hochgebirgsforschung. Erdkundliches, Wissen II, Wiesbaden. p.1-13.

VOGT, H.H. - 1971 - Kosmos Taschenlexikon; Wissenschaft von A bis Z: Natürwissenschaften und Medizin. Stuttgart, Franck'sche Verlags handlung.

WILHELMY, H. - 1974 - Klimageomorphologie in Stichworten. Kiel.

- - $1975-$ Die klimageomorphologischen Zonen und Hoehenstufen der Erde. Zeitschrift für Geomorphologie, N.F., Berlin, 19(4):353-376. 